Research Article

\title{
Investigation of Mechanical Numerical Simulation and Expansion Experiment of Expandable Liner Hanger in Oil and Gas Completion
}

\author{
Yong Chen $\left(\mathbb{D},{ }^{1}\right.$ Guo Ping Xiao, ${ }^{1}$ Wen Jian Zhong, ${ }^{2}$ and Hao $\mathrm{Yi}^{2}$ \\ ${ }^{1}$ School of Mechatronic Engineering, Southwest Petroleum University, Chengdu 610500, China \\ ${ }^{2}$ Research Institute of Petroleum Engineering, SINOPEC Northwest Oilfield Branch, Urumqi 830011, China \\ Correspondence should be addressed to Yong Chen; chyswpu@163.com
}

Received 5 February 2020; Revised 8 July 2020; Accepted 11 July 2020; Published 27 July 2020

Academic Editor: Reza Kolahchi

Copyright (c) 2020 Yong Chen et al. This is an open access article distributed under the Creative Commons Attribution License, which permits unrestricted use, distribution, and reproduction in any medium, provided the original work is properly cited.

The expansion experiment of the expansion liner hanger is a one-time failure process, so in order to save cost, the finite element technology needs to be used to simulate the expansion experiment. Obtaining the mechanical parameters of the expansion liner hanger can effectively optimize the size of the expansion liner hanger structure and guide the expansion completion. Firstly, main structure and principle of expandable liner hanger were introduced. Secondly, mechanical equilibrium equations of the expandable process were established to obtain pressure of the expandable fluid, and pressure of the expandable fluid is obtained. Thirdly, finite element (FE) simulation mechanical model of the expansion of the $\varnothing 244.5 \mathrm{~mm} \times \varnothing 177.8 \mathrm{~mm}$ expandable liner hanger was established to analyze the hang mechanism and the change rule of mechanical parameters during the expansion. The FE results have shown that radial displacement and residual stress of the inner wall of hanger varied in 5 cycles, and the expansion ratio of the expandable tube was $7.4 \%$ during the expansion. The expansion force did not change stably but gradually increased in stages. And the hydraulic pressure required for the expandable cone to continuously move down was $18 \mathrm{MPa}$. According to the contact stress generated on five rubber cylinders and the contact stress generated on five metal collars, the total hang force has been calculated, which exceeds $1000 \mathrm{kN}$ and meets the design requirements. Lastly, the expansion test results have shown that expansion pressure was $19 \mathrm{MPa}$, and the expansion rate was $7.1 \%$. The mechanical analysis results of the expandable liner hanger were in good agreement with the experiment results in this study, which provide important mechanical parameters for well completion with expandable liner hanger.

\section{Introduction}

The liner hanger is an important tool in the oil and gas completion. In the conventional liner hanger system [1-6], the liner is placed on the upper casing with the cone and the slip, and the liner overlap section has the poor sealing quality. The failure of hang and sealing of conventional liner hangers often occurs in the complex down hole conditions in deep wells, ultradeep wells, horizontal wells, multilateral well, etc. and seriously affects the well completion.

With the progress of the expandable pipe technology, the expandable liner hanger [7-15] is developed to help overcome the shortcomings of the conventional liner hanger. The expandable liner hanger applies the expansion principle, i.e., the metal plastic strain characteristics of the expandable pipe and exerts the radial expansion on the expandable hanger with the mechanical force, the hydraulic pressure, or both. The expandable body is attached to the outer casing, which is compressed by the residual stress, and the liner string is hanged with the friction force. The rubber cylinders are generally placed on the hanger body to improve the sealing and hang capability. The rubber materials are squeezed into the annulus between the hanger and the upper casing, effectively seal the annulus, and have an efficient two-way pressure-bearing capacity. Compared with the conventional liner hanger, the expandable liner hanger has the following characteristics: the packer and the hanger are integrated, and the seal assembly can withstand the high pressure and has 
the anticorrosion performance. The expandable liner hanger has no pressure-transmitting hole, which eliminates the potential leakage. When the liner is blocked, the liner hanger tool rotates the liner and circulates the killing fluids, which increases the tripping in depth of the liner and does not cause physical damage on the upper casing. Meanwhile, the expandable hanger has no external attachments such as slips and cones, which reduces the annular space occupied by the hangers, thereby increasing the available space inside the hanger and liner and improving the inside flow.

The expandable liner hangers have been applied in more than 2,000 well-times overseas [16-21], which lower the potential down hole risk of the conventional liner hanger and the poor sealing quality of the overlapped section and improves the stability of the liner cementation system. The Drilling Engineering Research Institute of CNPC XIBU Drilling Engineering Company Limited started the development of ELH-1 expandable liner hanger in 2011 [18] and completed trial production, indoor evaluation, etc. of the $\varphi 245 \mathrm{~mm} \times \varphi 178 \mathrm{~mm}$ expandable liner hanger prototype. In 2014, the expandable hanger developed by SINOPEC Shengli Oilfield Drilling Institute helped the Jidong Oilfield realize the first sidetracking in $\varphi 177.8 \mathrm{~mm}$ cased-hole and achieve the hang of $\varphi 139.7 \mathrm{~mm}$ on the $\varphi 177.8 \mathrm{~mm}$ intermediate casing with the expandable liner hanger [22]. In 2015, the Drilling Research Institute of the CNPC Great Wall Drilling Company developed a new type metal collar expandable liner hanger, which realizes hang and sealing of the liner through the metal interference contact after the expandable tube expansion and is characterized by strong hang and sealing performance, high temperature resistance, short overlapped section, and large drift diameter. The sealing pressure difference greater than $40 \mathrm{MPa}$, the temperature resistance higher than $350^{\circ} \mathrm{C}$ and the hang force greater than $1000 \mathrm{kN}$ meet the sealing performance requirements in the heavy oil thermal recovery [23]. However, these studies did not take an effective method to systematically discuss and evaluate the mechanical properties and suspension capacity of expansion liner hanger. The drilling technology in China goes to deep wells and ultradeep wells where the probability of drilling complex formations increases and the down hole conditions are more complicated, which needs the research and development of expandable liner hangers. The expandable liner hanger ensures implementation of China' strategy of exploring deep oil and gas resources and enhances China's deep drilling capability.

Obtaining the mechanical parameters of the expansion liner hanger can effectively guide the research and development of expandable liner hangers and expansion completion operation. At present, physical experiment and finite element simulation are the most commonly used methods to obtain mechanical parameters. However, the physical experiment method has a high cost, a long cycle, and more personnel involved. With the rapid development of the computer hardware and the finite element (FE) theory [24-30], the computer simulation is applied in various industries. The simulation in the FE software is used as a tool for pretest verification and posttest optimization, which greatly reduces the test period and the test cost.

\section{Structure and Principle of Expandable Liner Hanger}

Structure of the expansion portion of the expansion liner hanger designed in this study mainly includes the expandable cone assembly, the rubber cylinder (5 pieces), the expandable tube, the outer casing, the mandrel, and the pressure relief sleeve, as shown in Figure 1. The models of the expandable cone, 5 rubber cylinders, the expandable tube, and 10 metal convex collars are shown in Figure 2. The expandable structure is set as a state before expansion in the outer casing. The rubber cylinders are equally spaced on the expandable tube and are axially separated and positioned by the metal collar.

Working principle of the expansion liner hanger: the high-pressure fluid enters the internal part of the expandable liner hanger, forming a large pressure difference on both sides of the expandable cone and pushing the expandable cone to move down. As the outer diameter of the expandable cone is larger than the inner diameter of the hanger body, cone radially expands the hanger body, and thus, the plastically deformed hanger body is firmly attached to the inner wall of the outer casing. When the cone moves down to the designed position, the pressure relief sleeve is pushed, the pin is sheared, the pressure relief hole is exposed, the pressure of the expandable fluid is released, and the expansion operation is completed. The hang force consists of two parts: the first is the friction force generated by the rubber cylinder squeezed into the annulus between the hanger and the upper casing due to plastic deformation of the expandable tube, and the second is the contact force due to contacting deformation between the convex metal collar and the outer casing during the expansion.

\section{Mechanical Equilibrium Equations of the Expandable Process}

According to the research literature of relevant shell structures [31-35], assuming that the expansion cone is expanded uniformly and is considered as a quasi-static process, the force on the expandable cone is shown in Figure 3.

The geometric parameters in Figure 3 include the initial inner diameter $r_{0}$, the initial wall thickness $t_{0}$, the inner diameter after expansion $r_{1}$, and the wall thickness after expansion $t_{1}$. The main parameters of the expandable cone in Figure 3(b) include the cone height $\mathrm{H}$ and the cone angle $\alpha$. If the hanger body reaches a stable condition during the expansion, the expansion cone is in a state of mechanical equilibrium, the forces include the contact pressure $q_{m}$ between the expandable cone and the expandable tube, and the friction force $f$ and the expandable force $\mathrm{F}$ were applied to the expandable cone.

The lateral area of the expandable cone can be obtained from the geometric relationship in the figure: 


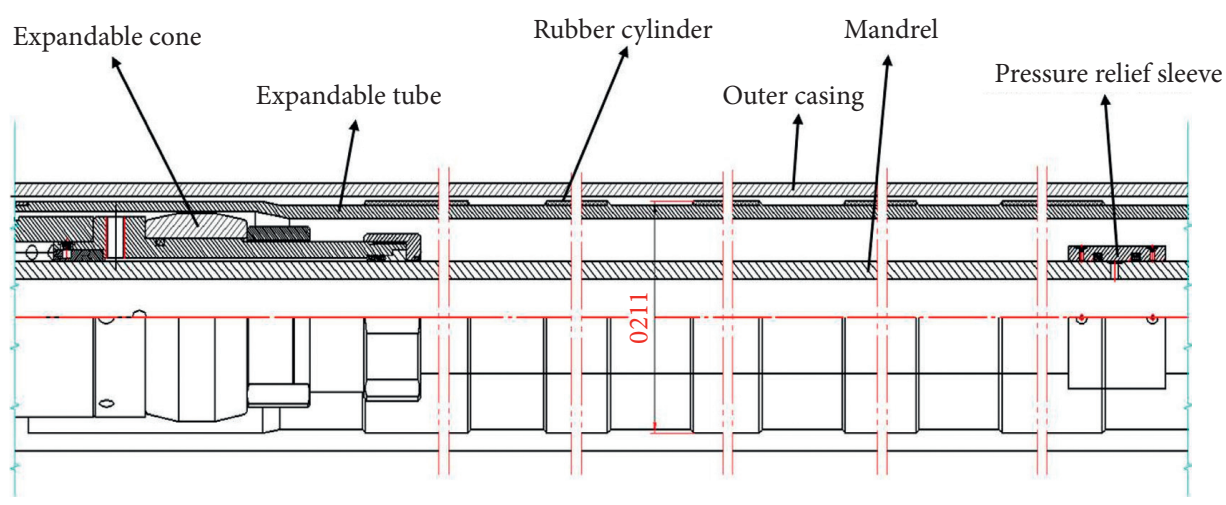

Figure 1: Structure of the expansion portion of the expansion liner hanger.

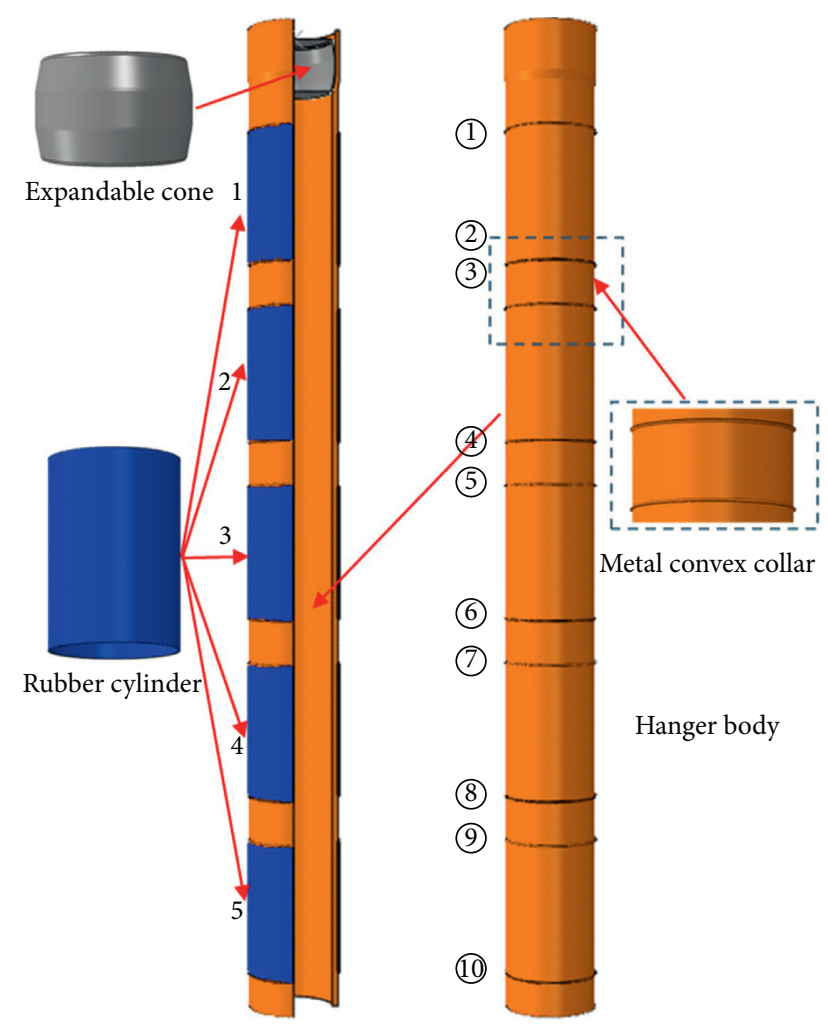

FIGURE 2: Hanger components of expandable liner hanger.

$$
A=\frac{\pi\left(r_{1}^{2}-r_{0}^{2}\right)}{\sin \alpha}
$$

According to the axial mechanical equilibrium of the expandable cone, we obtain

$$
F=q_{m} A \sin \alpha+\mu q_{m} A \cos \alpha .
$$

The force distribution of the hanger is shown in Figure 4. The expandable tube is longitudinally sectioned along its $Z$ axis for mechanical analysis.

According to the mechanical equilibrium equation on the $Z$ axis, we obtain axial principal stress $\sigma_{z}$ :

$$
\sigma_{z}=\frac{\left(r_{1}^{2}-r_{0}^{2}\right)(1+\mu \cot \alpha) q_{m}}{\left(r_{1}+t_{1}\right)^{2}-r_{1}^{2}}
$$

According to the geometric relationship, the component of the friction on the $x$-axis is established as

$$
F_{x}(f)=\left(r_{1}+r_{0}\right) H f \tan \alpha .
$$

According to the mechanical equilibrium in the $x$-axis, we obtain

$$
\sigma_{\theta}=\frac{\left(r_{1}+r_{0}\right)(1-\mu \tan \alpha) q_{m}}{t_{0}+t_{1}} .
$$

Considering that the tensile deformation of the metal is the Hollomon relationship between the true stress and the true strain in the stage of uniform plastic deformation, we obtain

$$
\sigma=K \varepsilon^{n}
$$

where $\sigma$ is the true stress, $K$ is the hardening coefficient, $\varepsilon$ is the true strain, and $n$ is the hardening index.

As $\sigma_{\theta}, \sigma_{r}$, and $\sigma_{z}$ are the principal stresses and $\sigma_{\theta}>\sigma_{r}>\sigma_{z}$, the equivalent stress of the microelement is obtained according to the Mises yield criterion:

$$
\sigma_{\theta}-\sigma_{z}=1.15 \sigma_{\text {eqv }}
$$

The pressure of the expandable fluid is obtained by combining formulas (3)-(7):

$$
P=\frac{1.15 K \varepsilon^{n}\left(r_{1}-r_{0}\right)\left(t_{0}+t_{1}\right)\left(2 r_{1}+t_{1}\right) t_{1}(1+\mu \cot \alpha)}{\left[\left(2 r_{1}+t_{1}\right) t_{1}(1-\mu \tan \alpha)-\left(r_{1}-r_{0}\right)\left(t_{0}+t_{1}\right)(1+\mu \cot \alpha)\right] r_{1}^{2}}
$$

where 


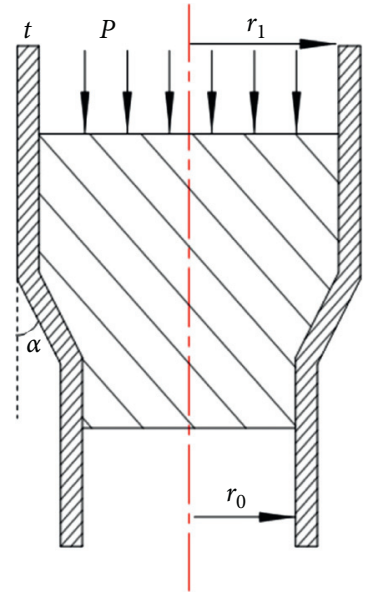

(a)

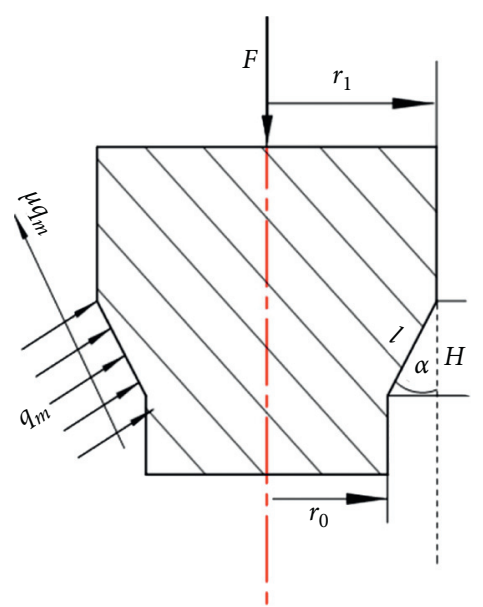

(b)

Figure 3: Mechanical equilibrium model of expansion inside the hanger.

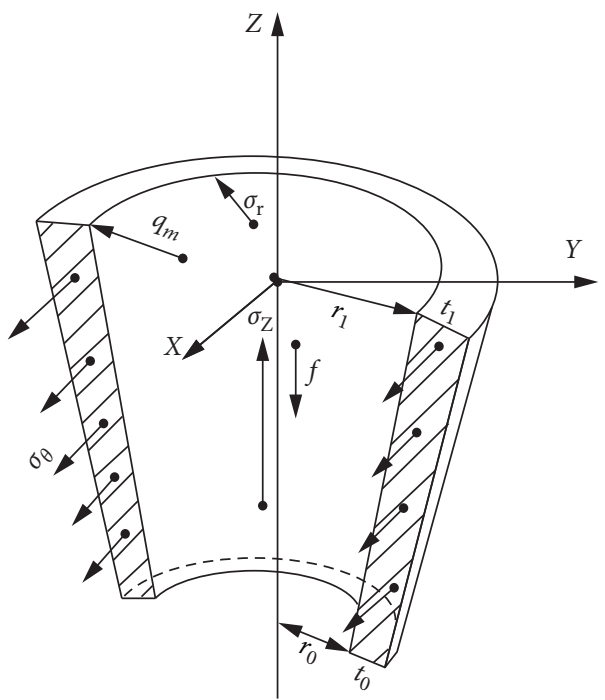

FIGURE 4: Distribution of forces applied to the expandable tube.

$$
q_{m}=\frac{1.15 K \varepsilon^{n}\left(t_{0}+t_{1}\right)\left(2 r_{1}+t_{1}\right) t_{1}}{\left(r_{1}+r_{0}\right)\left[\left(2 r_{1}+t_{1}\right) t_{1}(1-\mu \tan \alpha)-\left(r_{1}-r_{0}\right)\left(t_{1}+t_{0}\right)(1+\mu \cot \alpha)\right]} .
$$

\section{Numerical Simulation of Expandable Liner Hanger}

4.1. Finite Element Mechanical Model. The expansion deformation of the expandable liner hanger covers the plastic deformation of the metal, the compression of rubber materials, and multiple contacts, which are considered as a complex nonlinear problem and cannot be calculated with traditional analytical methods. The literature research shows that the research on the expansion mechanism and calculation on parameters of the expandable liner hanger with the
FE software is feasible $[36,37]$. Considering that the outer casing, the expandable tube, and the expandable cone are circumferential parts with respect to the central axis, the boundary conditions and loads are symmetrical about the center axis, and in order to save the time of the calculation, an axisymmetric model of the expandable liner hanger is established. The expandable cone is made of a material with high rigidity and strength and is regarded as a rigid body when establishing the FE model, as shown in Figure 5. In the finite element model, element type of expansion tube, rubber cylinder, and outer casing is CAX4R. The number of 


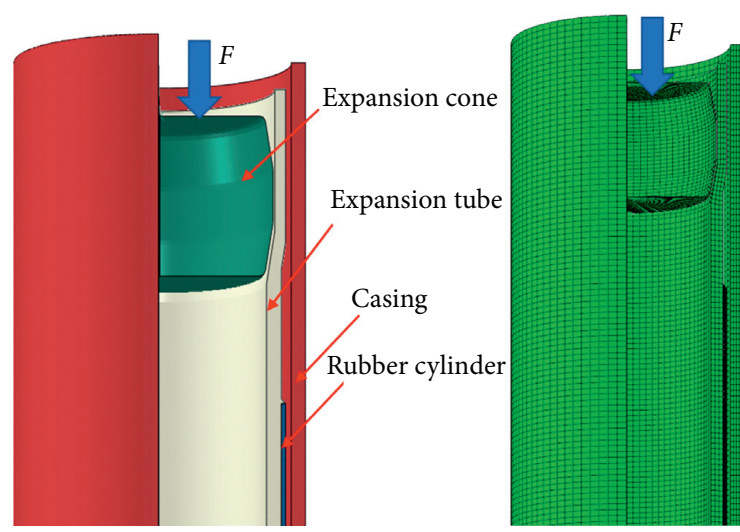

FIGURE 5: The FE model of expandable liner hanger.

expansion tube grids is 1450 , the number of rubber cylinder grids is 3256, and the number of outer casing grids is 1600 . The boundary conditions and loads are set as follows: the expansion tube and outer casing are fixed axially, and the downward velocity of $0.5 \mathrm{~m} / \mathrm{s}$ is applied to the expansion cone.

4.2. Geometric Parameters and Material Parameters of the Model. The size of hanger is $\varphi 244.5 \mathrm{~mm} \times \varphi 177.8 \mathrm{~mm}$, the outer diameter $\varphi 204 \mathrm{~mm}$, the inner diameter $\varphi 179 \mathrm{~mm}$, the rubber cylinder length $300 \mathrm{~mm}$, the rubber cylinder wall thickness $3.6 \mathrm{~mm}$, the expandable cone outer diameter $\varphi 190 \mathrm{~mm}$, the length of expandable plastic deformation part $2300 \mathrm{~mm}$, and the outer casing diameter $\varphi 244.5 \mathrm{~mm}$. Some material parameters of the components are shown in $\mathrm{Ta}-$ bles 1 and 2 .

The rubber cylinder is made of modified nitrile rubber. The Mooney-Rivlin model is used to describe the superelasticity of the rubber cylinder with Mooney constants $C_{01}$ and $C_{10}$ and the incompressibility ratio $D_{1}$.

The relationship among the elastic modulus $E$ and the shear modulus $G$ and the rubber material constant is expressed as follows [37]:

$$
\begin{aligned}
& G=2\left(C_{10}+C_{01}\right), \\
& E=6\left(C_{10}+C_{01}\right) .
\end{aligned}
$$

\section{Finite Element Calculation Result}

The expansion rate of the hanger body, the expansion force pushing the expandable cone to move downward, and the hang force are main mechanical parameters in the study of the expandable liner hanger [38-51]. The visualization module in FE software is used to obtain parameters such as the contact stress between the rubber cylinder and the outer casing, the counter force of the expandable cone, and the radial expansion displacement of the expandable tube and indirectly calculate the minimum hydraulic thrust, the hang force, etc.

5.1. Expansion Rate of the Liner Hanger Body. The expansion rate of the liner hanger is an index determining the plastic deformation of the material of the expandable tube and the
TABLE 1: Metal material parameters.

\begin{tabular}{lcccc}
\hline $\begin{array}{l}\text { Structure } \\
\text { name }\end{array}$ & $\begin{array}{c}\text { Density } \\
\left(\mathrm{kg} / \mathrm{m}^{3}\right)\end{array}$ & $\begin{array}{c}\text { Young's } \\
\text { modulus } \\
(\mathrm{MPa})\end{array}$ & $\begin{array}{c}\text { Poisson's } \\
\text { ratio }\end{array}$ & $\begin{array}{c}\text { Yield } \\
\text { strength } \\
(\mathrm{MPa})\end{array}$ \\
\hline $\begin{array}{l}\text { Expandable } \\
\text { body }\end{array}$ & 7800 & 207000 & 0.264 & 530 \\
\hline $\begin{array}{l}\text { Outer } \\
\text { casing }\end{array}$ & 7850 & 207000 & 0.28 & 860 \\
\hline
\end{tabular}

TABLE 2: Nitrile rubber parameters.

\begin{tabular}{lcc}
\hline$C_{10}(\mathrm{MPa})$ & $C_{01}(\mathrm{MPa})$ & $D_{1}$ \\
\hline 1.84 & 0.49 & 0.0214 \\
\hline
\end{tabular}

available space inside the hanger and the casing. It refers to the ratio of the difference between the diameter after expansion and the diameter before expansion to the diameter before expansion. The formula is written as follows:

$$
\delta=\frac{D_{1}-D}{D}
$$

where $D_{1}$ is the diameter after expansion of the expandable tube and $D$ is the diameter before expansion of the expandable tube.

The radial displacement cloud diagram of the expandable liner hanger after expansion is shown in Figure 6, and the maximum radial displacement of the hanger body is $7.57 \mathrm{~mm}$. As the model is axisymmetric, the expansion value of the expandable body is $15.14 \mathrm{~mm}$. The size of the hanger tube is $204 \mathrm{~mm}$, and according to formula (11), the expansion rate is $7.4 \%$.

Figure 7 shows the relation between the radial displacement of the expandable tube inner wall and the axial path of the expandable tube. The five rubber cylinders are axially equally spaced by the metal convex collar on the expandable tube (Figure 2), which causes five cyclic displacement variation during the expansion.

5.2. Calculation of Expansion Pressure. The expansion force is the axial driving force applied to the expandable cone during the expansion operation. It is the basic parameter for the expansion deformation of the hanger body and is also the raw data for the design of the expansion structure. The expansion force is mainly composed of two parts: one is overcoming the friction of the contact surfaces, and another is internal energy consuming the internal uneven deformation.

The expansion force is the basis for selecting the ground pressure equipment. The expansion force directly determines whether the pressure equipment can continuously move the expandable cone downward to push the expandable tube to expand and deform. With the postprocessing in FE software, the expansion force of the expandable cone along the axial path is obtained when the expandable cone moves downward (Figure 8). During the expansion, the expansion force does not vary uniformly but gradually increases in stages. 
$U, U 1(\mathrm{~mm})$

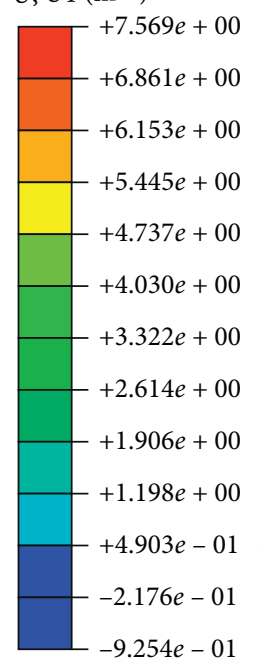

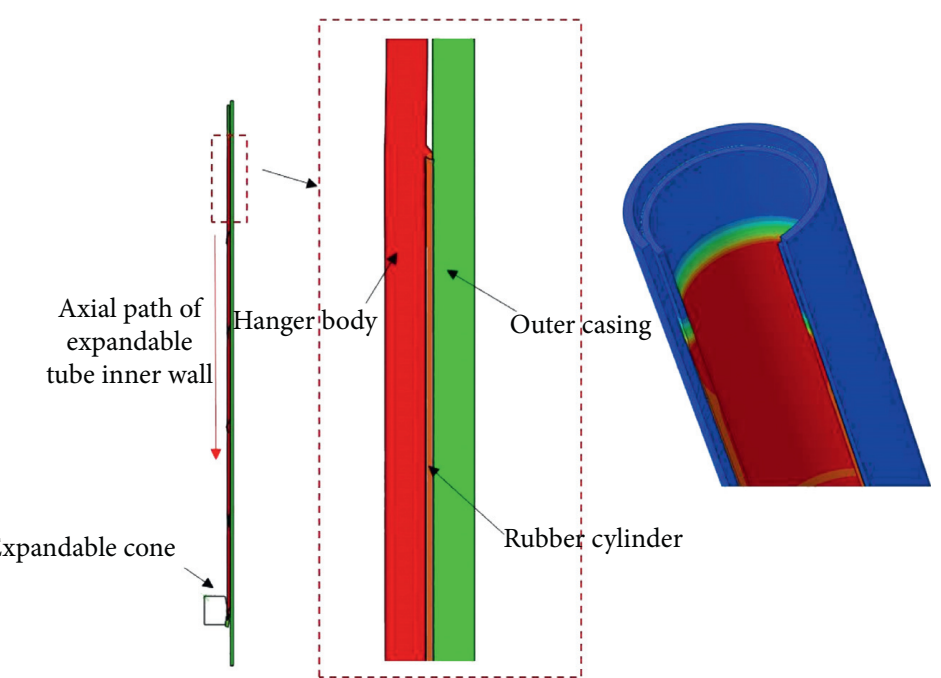

FiguRE 6: Radial displacement cloud diagram of the expandable liner hanger after expansion.

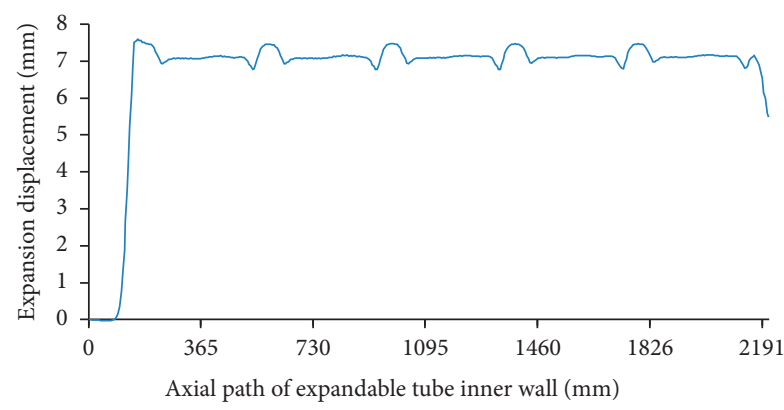

Figure 7: Relation between the radial displacement of the expandable tube inner wall and the axial path of the expandable tube.

Taking the maximum value $352 \mathrm{kN}$ of axial counter force $F_{\max }$ in Figure 8 as the basis for calculating maximal expansion pressure $P_{\max }$, where $S_{e}$ is the area of pressure action:

$$
P_{\max }=\frac{F_{\max }}{S_{e}} .
$$

The hydraulic pressure for continuous downward movement of the expandable cone is $18 \mathrm{MPa}$. So the ground pressure equipment is required to provide the hydraulic pressure $18 \mathrm{MPa}$ to expand the expandable liner hanger. The pressure capacity of China's field operation ground pipe meets the requirements for pressurization.

5.3. Analysis of Equivalent Stress. During the expansion, the hanger body is subjected to mechanical internal compression force, which causes a large plastic deformation. Figure 9 shows the equivalent stress generated on the hanger body during the expansion. The maximum equivalent stress reaches $530 \mathrm{MPa}$, which exceeds the yield strength of the hanger body. As the body is deformed, the hanger is closely attached to the inner wall of the outer casing by compressing the rubber cylinder after the expansion. Figure 10 shows the residual stress generated on the inner wall of the hanger

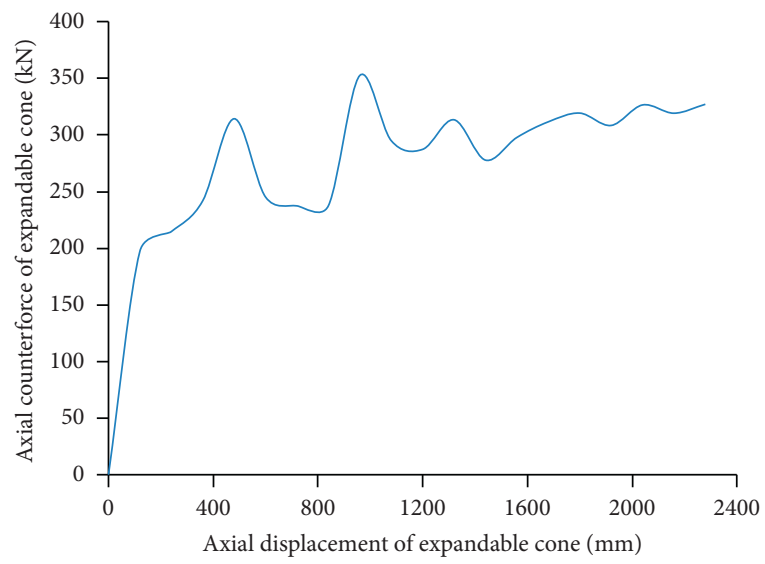

Figure 8: Expandable force generated on the expansion cone during the expansion.

body after the expansion. The metal convex collars placed on the outer wall of the hanger body at equal intervals cause the cyclic variation in residual stress axially.

5.4. Calculation of Hang Force. The hang force is a parameter characterizing the mechanical properties of the expandable hanger. The hang force consists of two parts: the first is the friction force generated on the rubber cylinders squeezed into the annulus between the hanger and the upper casing due to plastic deformation of the expandable pipe, and the second is the hang force generated by the metal convex collars, which contact the outer casing and are embedded in the inner wall of the outer casing during the expansion. The formula for the hang force is as follows:

$$
F_{T}=F_{R}+F_{M} \text {, }
$$

where $F_{T}$ is the total hang force, $F_{R}$ is the hang force generated by the rubber cylinder, and $F_{M}$ is the hang force generated by metal convex collars. 


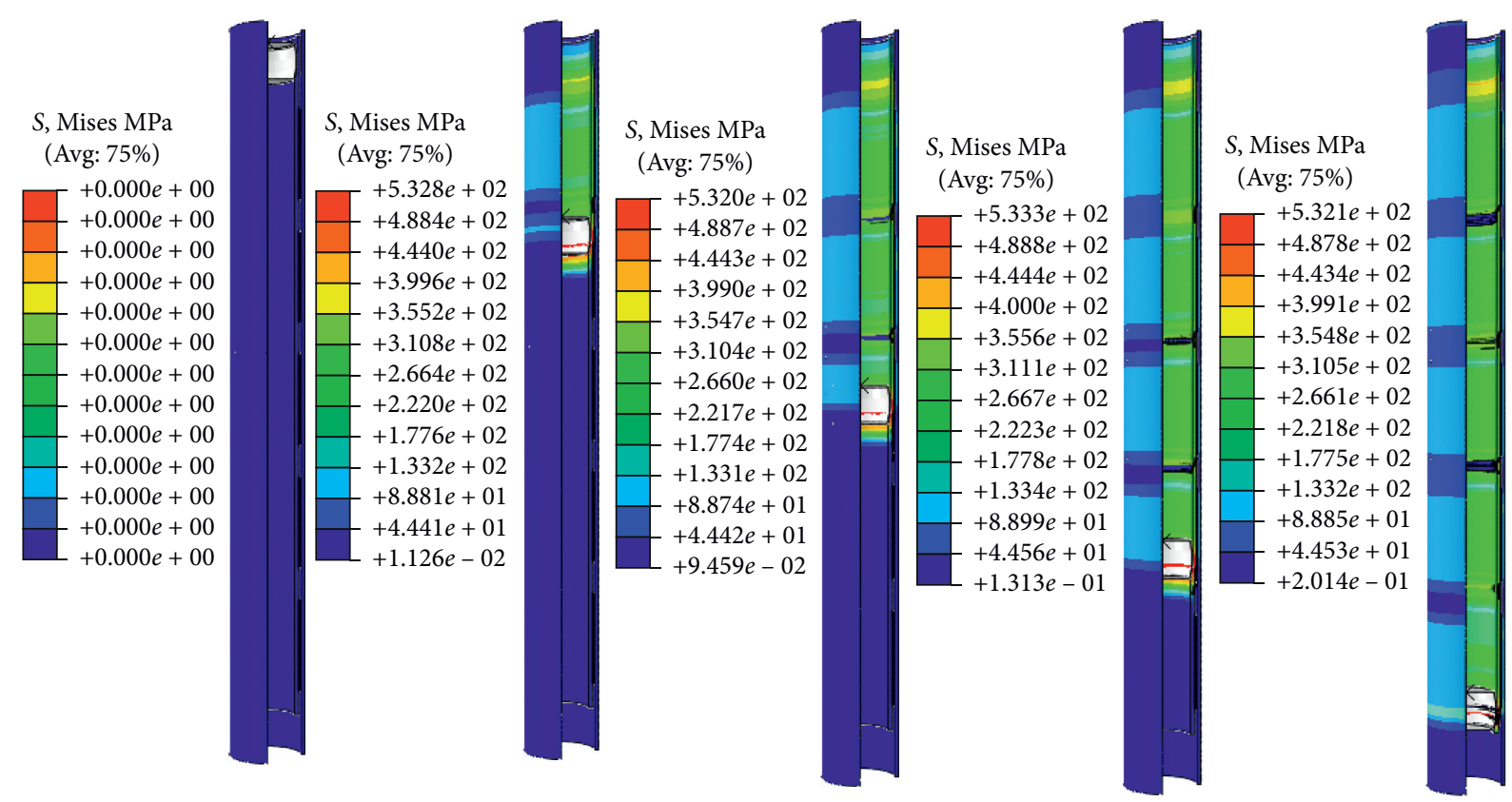

FIgURE 9: Cloud diagram of equivalent stress generated on the hanger body during the expansion.

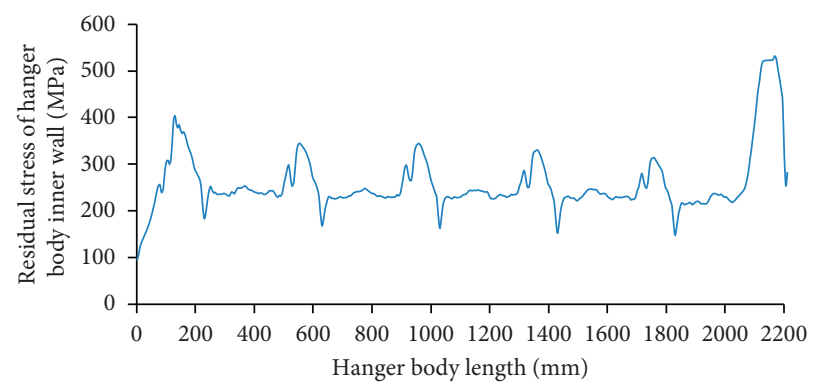

FIGURE 10: Residual stresses generated on the inner wall of the hanger body after expansion.

5.4.1. Hang Force Generated by the Rubber Cylinder. The contact stress between the inner wall of each rubber cylinder and the expandable tube and that between the outer wall of each rubber cylinder and the outer casing are calculated by FE numerical simulation. The rubber cylinder is made of hyperelastic material, and it is elongated and deformed axially after radial compression and deformation. The axial extension part of the rubber cylinder goes beyond the metal collar. The deformed rubber cylinder is divided into two parts: the first part is the contact region with the inner wall of the casing, and another is the noncontact region (shown in Figures 11-15). The data points along the axial path $a-b$ are averaged to obtain the average contact stress value on the rubber cylinder wall (Figures 11-15). The hang force of a single rubber cylinder is calculated with the friction on the inner and outer walls.

As the rubber cylinder has a relatively small thickness, the effective contact area between the inner and outer walls of rubber cylinder is considered to be uniform before and after compression, and the inner wall is considered as the effective contact area:

$$
F_{i R}=2 f_{R} \times A_{o} \times \sigma_{i R}
$$

where $F_{i R}$ is the hang force of the $i$ rubber cylinder; $f_{R}$ is the friction coefficient between the rubber cylinder and the inner and outer tube walls, $f_{R}=0.15$ in this paper [30]; $A_{O}$ is the effective contact area between the rubber cylinder and the inner and outer tube walls, $\mathrm{mm}^{2}$; and $\sigma_{i R}$ is the average contact stress of the inner and outer walls of the $i$ rubber cylinder, MPa.

The hang force generated on each rubber cylinder is calculated according to the FE analysis and formula (14), as shown in Figure 16. The hang force gradually increases from the rubber cylinder 1 to the rubber cylinder 5 , and the total hang force of five rubber cylinders is $F_{R}=1112 \mathrm{kN}$.

5.4.2. Hang Force Generated by Metal Convex Collar. In addition to the compression deformation of the rubber cylinder, the radial expansion deformation of metal convex collar and the contact with the inner wall of outer casing 


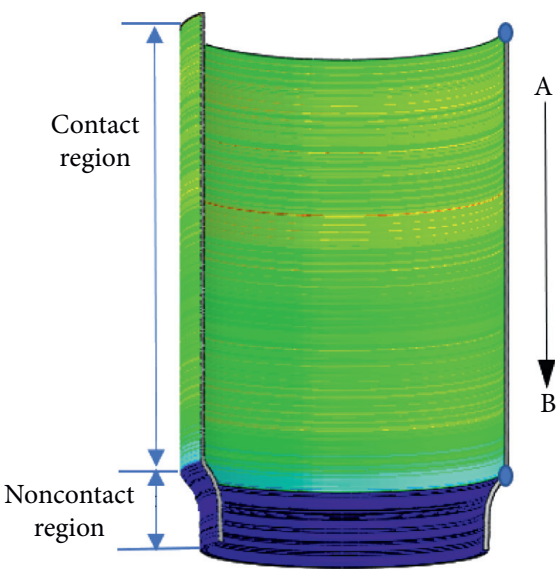

(a)

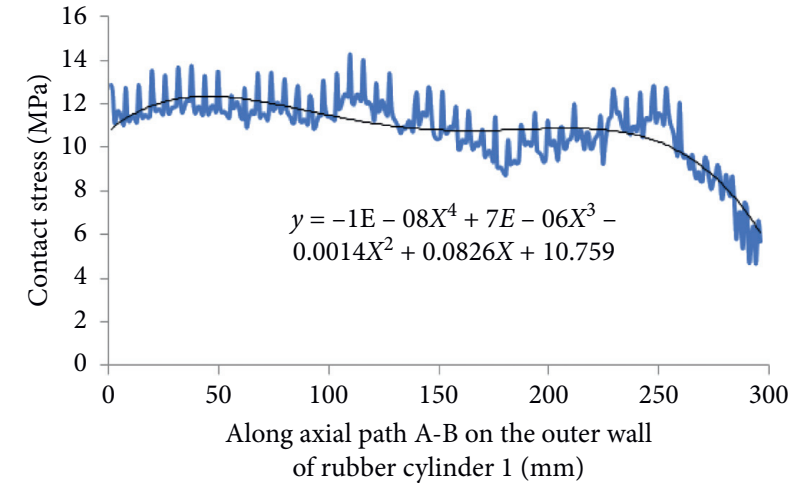

(b)

Figure 11: Contact stress variation in the rubber cylinder 1 and the average contact stress along the axial path on the outer wall of the rubber cylinder during the expansion.

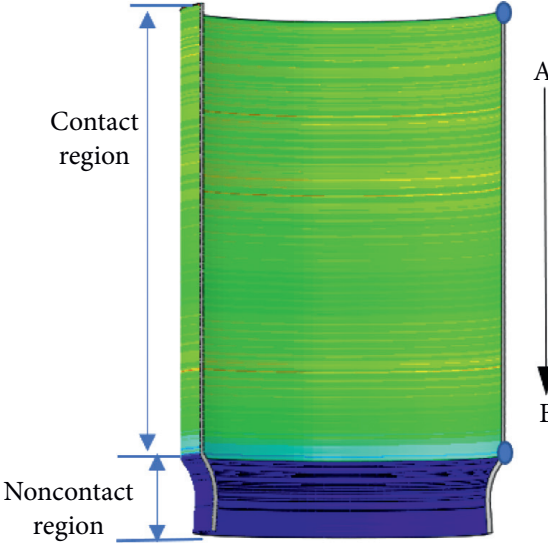

(a)

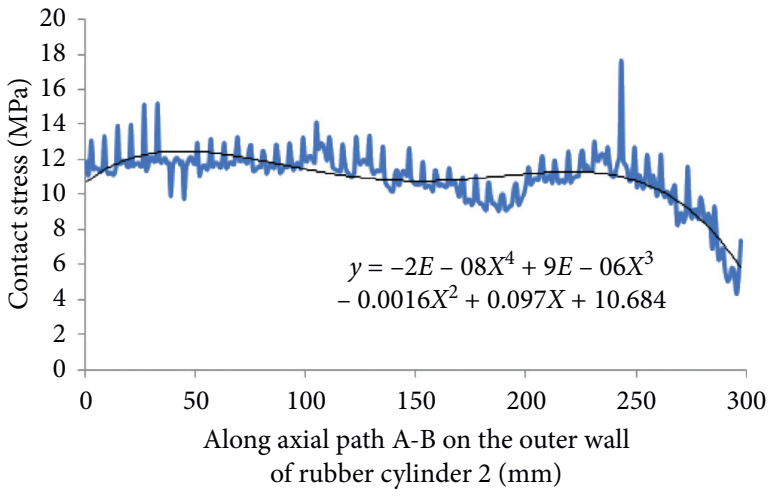

(b)

FIGURE 12: Contact stress variation in the rubber cylinder 2 and the average contact stress along the axial path on the outer wall of the rubber cylinder during the expansion.

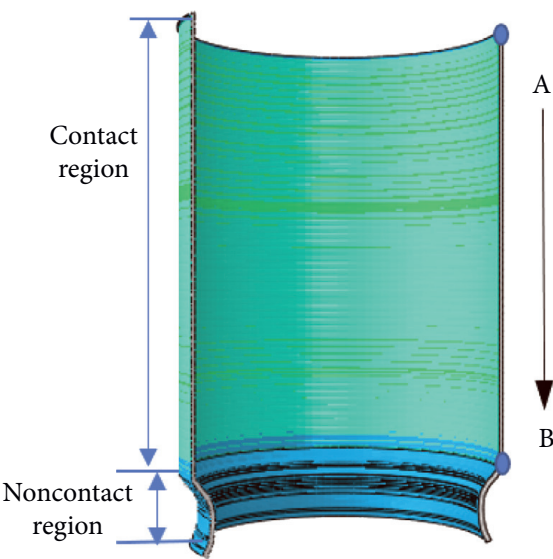

(a)

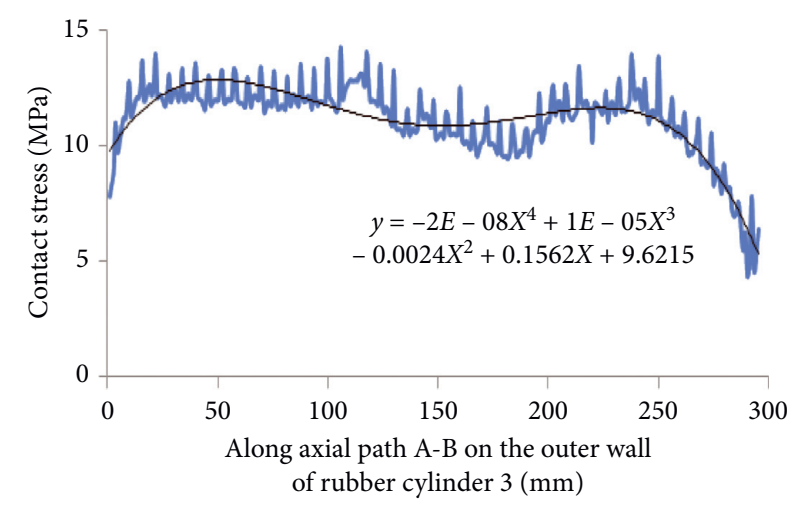

(b)

Figure 13: Contact stress variation in the rubber cylinder 3 and the average contact stress along the axial path on the outer wall of the rubber cylinder during the expansion. 


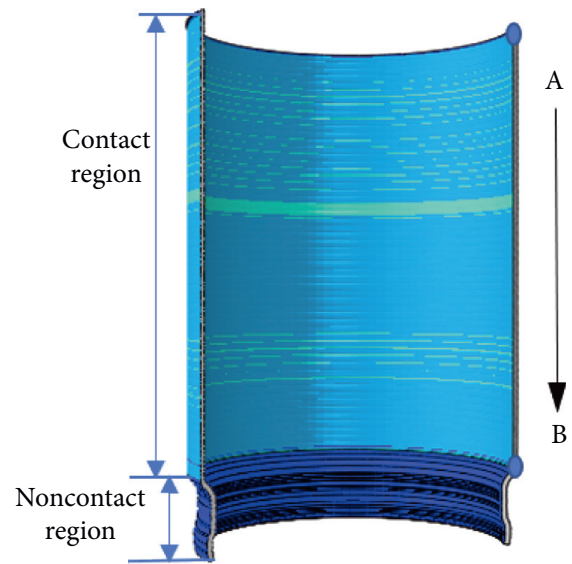

(a)

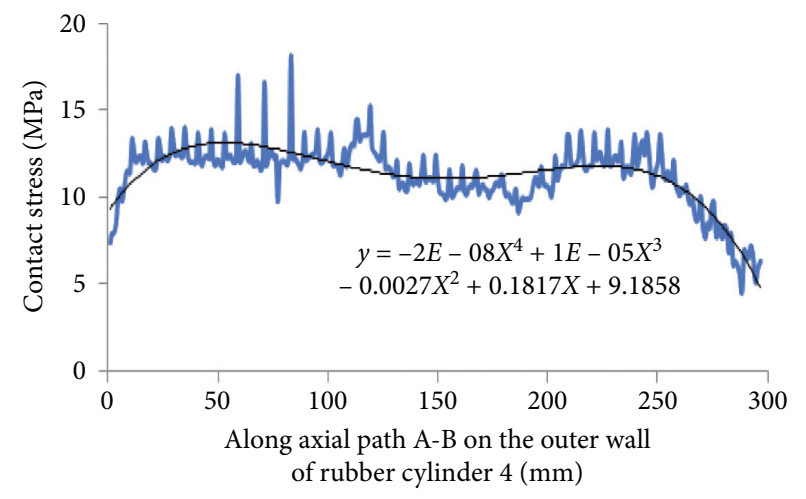

(b)

FIGURE 14: Contact stress variation in the rubber cylinder 4 and the average contact stress along the axial path on the outer wall of the rubber cylinder during the expansion.

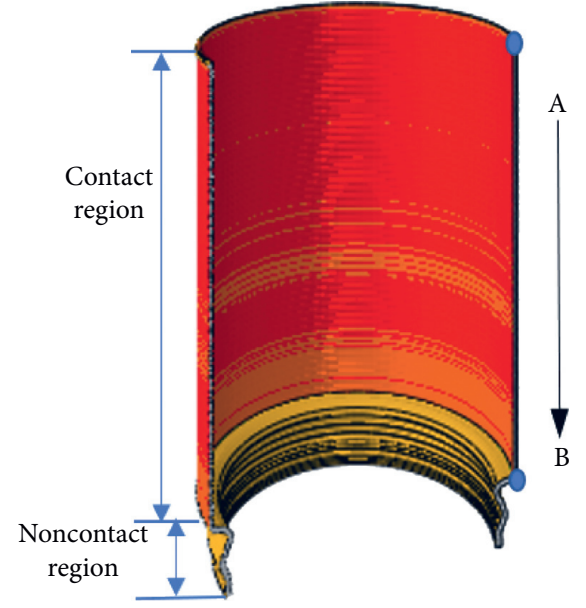

(a)

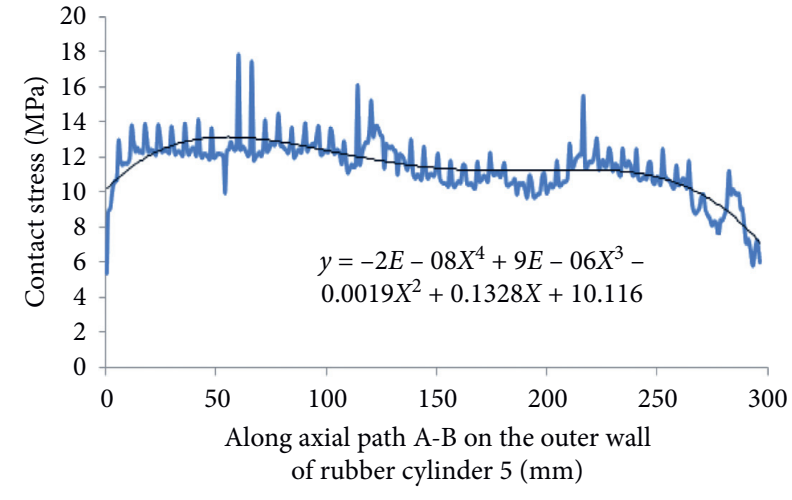

(b)

FIGURE 15: Contact stress variation in the rubber cylinder 5 and the average contact stress along the axial path on the outer wall of the rubber cylinder during the expansion.

result in the hang force. Similarly, the hang force on the metal convex collar is calculated with the method of calculating the hang force on the rubber cylinders.

In order to fix five rubber cylinders with equal intervals, five sets (10) of metal convex collars are processed on the hanger body. As the metal collar has the small size, a regional mesh refinement (Figure 17) shows the metal convex collar grid and deformation diagram. The contact stress value is extracted and averaged along the axial contact path $c-d$ between the metal convex collar and the casing (Figure 18). The average contact stress generated on the metal collars (1), (3), (5), (7), and (9) has a low value, and that generated on the metal collars (2), (4), (6), (8), and (10) has a high value.

The contact axial deformation length of the convex collar is $1.8 \mathrm{~mm}$, the average diameter after deformation is
$207 \mathrm{~mm}$, and the hang force of each metal convex collar is calculated with the formula as follows:

$$
F_{i m}=f_{m} \times A_{m} \sigma_{i m}
$$

where $f_{m}$ is the friction coefficient between the metal collar and the casing, $f_{m}=0.25$ [31]; $A_{m}$ is the effective contact area between the metal collar and the casing wall, $\mathrm{mm}^{2} ; \sigma_{i m}$ is the average contact stress between the metal collar and the casing wall, $\mathrm{MPa}$, shown in Figure 18; and $F_{i m}$ is the hang force generated on the metal convex collar, kN, shown in Figure 19:

$$
F_{m}=\sum_{i=1}^{10} F_{i m}=59.7 \mathrm{kN} \text {. }
$$

According to formulas (13)-(16), the total hang force of the expandable liner hanger is $F=1112 \mathrm{kN}+59.7 \mathrm{kN}=1171.7 \mathrm{kN}$. 


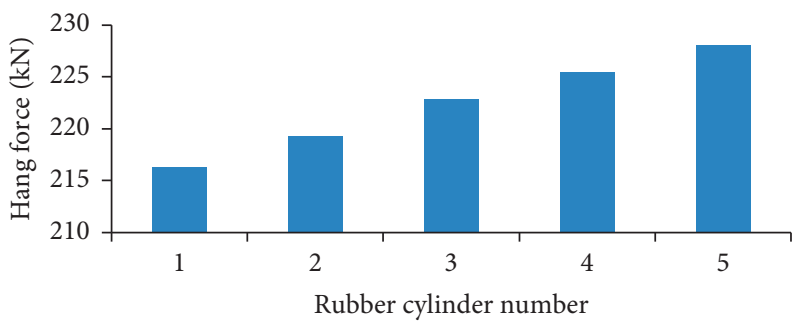

FIgURE 16: Hang force generated by each rubber cylinder.

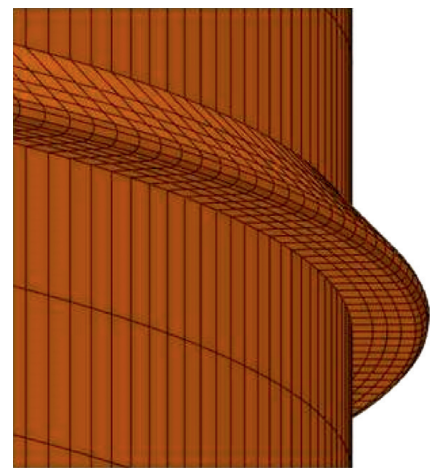

(a)

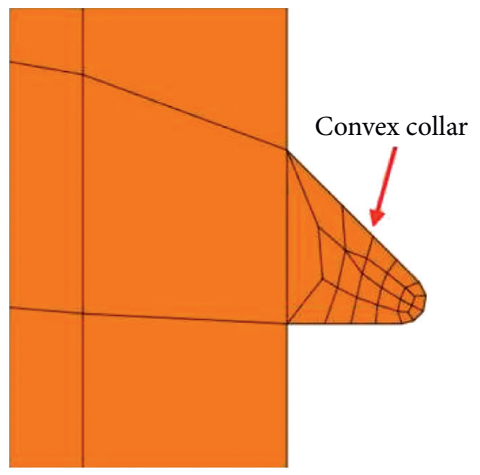

(b)

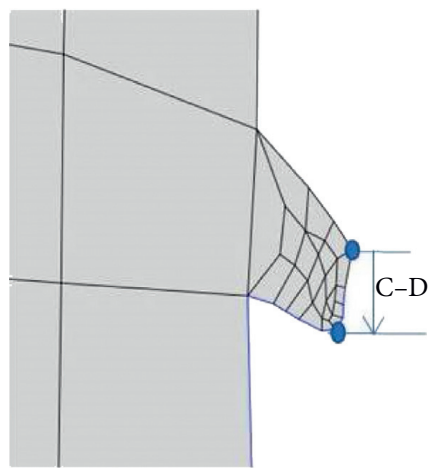

(c)

FIGURE 17: Metal convex collar grid and contact deformation diagram: (a) metal convex collar 3D diagram; (b) metal convex collar grid; (c) metal convex collar deformation diagram.

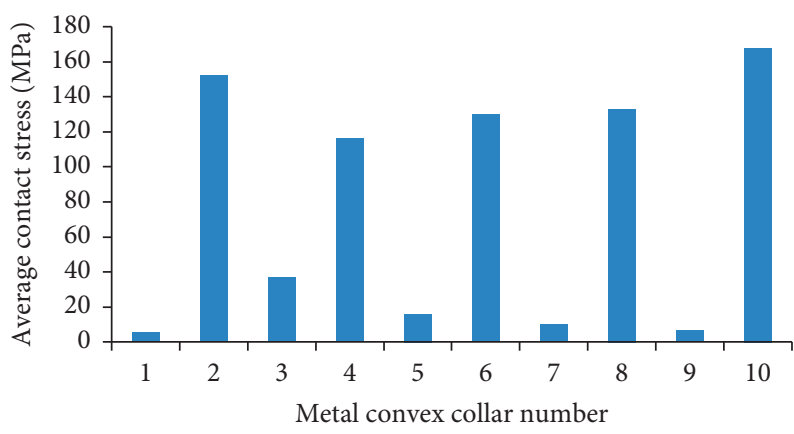

Figure 18: Average contact stress on each metal collar.

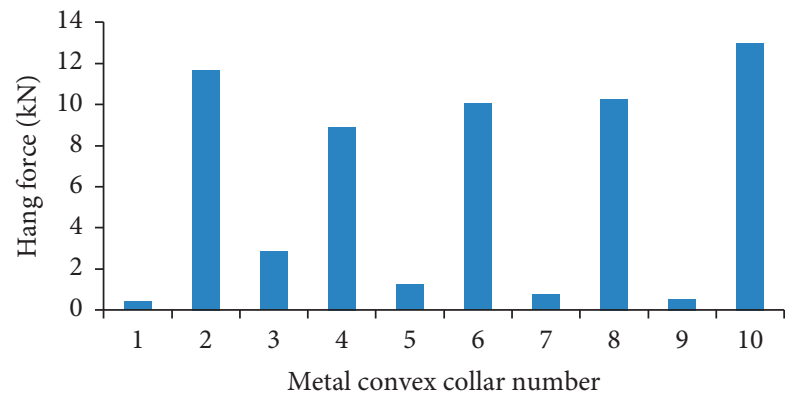

FIgURE 19: Hang force generated on each metal collar. 


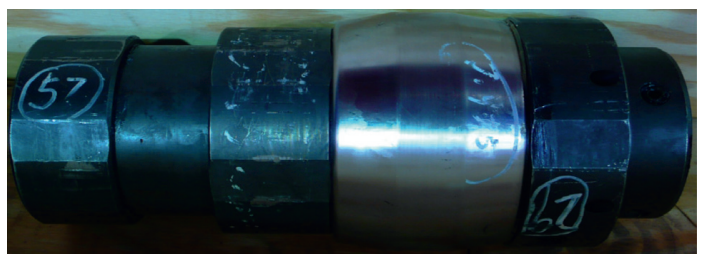

FIGURE 20: Expansion cone assembly.

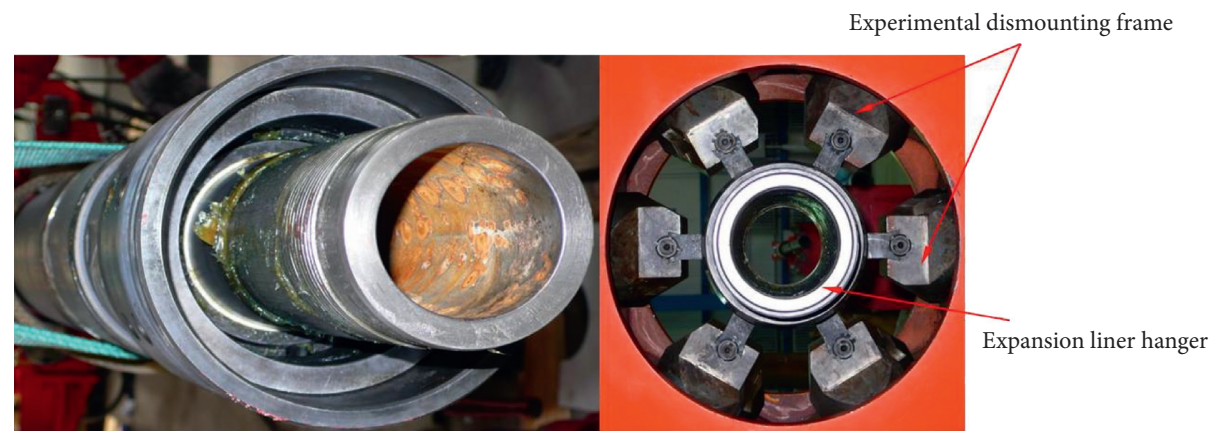

FIGURE 21: Expansion liner hanger supported with the experimental dismounting frame and kept it in a horizontal position.

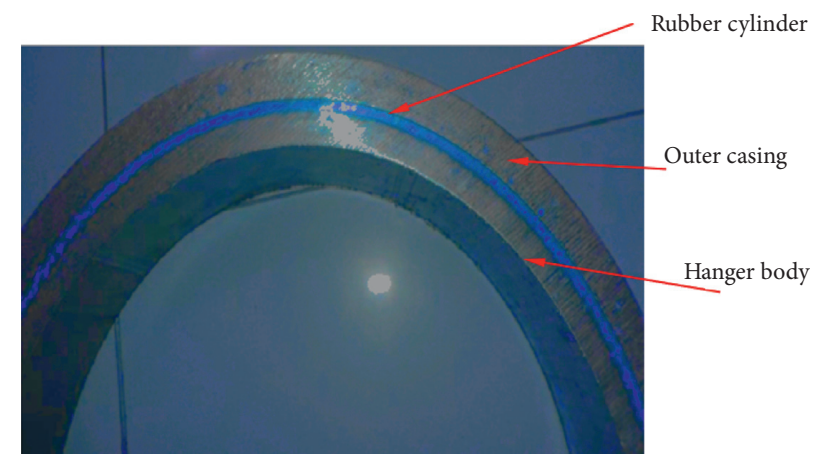

FIGURE 22: Rubber cylinder is completely squeezed between the hanger body and the outer casing.

\section{Expansion Test}

After assembling the processed parts of the expansion liner hanger, shown in Figure 20, support it with the experimental dismounting frame and keep it in a horizontal position (shown in Figure 21). The dimension parameters of key parts are as follows: the outside diameter of the expansion cone is $190 \mathrm{~mm}$, the inside diameter is $143 \mathrm{~mm}$, and the length is $121 \mathrm{~mm}$. The outer diameter of the liner hanger body is $204 \mathrm{~mm}$, the inner diameter is $179 \mathrm{~mm}$, and the expanded length is $4500 \mathrm{~mm}$. Conduct a low-pressure test ( $3 \mathrm{MPa}$ ) for 5 minutes to ensure that the sealing performance of each sealing component is sufficient. After the low-pressure test, prepare for the expansion test.

\subsection{Test Step}

(1) Use a pressure pump to slowly build the pressure through low displacement.
(2) Boosting the pressure to $19 \mathrm{MPa}$, the expansion cone begins to move forward, and the hanger body begins to expand and seal.

(3) The expansion cone is moved to the position of the pressure relief sleeve. The pressure relief sleeve is pushed, the pin is sheared, the pressure relief hole is exposed, the pressure drops, and the expansion operation is completed.

\subsection{Test Results}

(1) The expansion pressure in the test was $19 \mathrm{MPa}$, and the expansion pressure obtained by finite element analysis was $18 \mathrm{MPa}$, with the expansion pressure error of $5.3 \%$.

(2) By measuring the diameter of the hanger body after expansion and before expansion, the expansion rate is $7.1 \%$. By comparing the results of finite element analysis, the expansion rate error is $4 \%$. 
(3) After expansion, the rubber cylinder is completely squeezed between the hanger body and the outer casing, so as to realize sealing and suspension, as shown in Figure 22.

\section{Conclusion}

In this paper, a FE simulation mechanical model of the $\varnothing 244.5 \mathrm{~mm} \times \varnothing 177.8 \mathrm{~m}$ expandable liner hanger is established. The conclusions are as follows:

(1) When the hanger body is expanded, its radial displacement and the residual stress of the inner wall vary in 5 cycles due to that the five rubber cylinders are axially equally spaced by the metal convex collar on the expandable tube, and the expansion ratio of the expandable tube is $7.4 \%$.

(2) The variation in the expansion force is indirectly calculated with the axial reaction force applied to an expandable cone. The expansion force does not vary uniformly but gradually increases in stages. The hydraulic pressure required for pushing the expandable cone to move down is $18 \mathrm{MPa}$.

(3) According to the contact stress generated on five rubber cylinders and the contact stress generated on ten metal collars, the total hang force has been calculated, which exceeds $1000 \mathrm{kN}$ and meets the design requirements.

(4) The FE mechanical analysis results of the expandable liner hanger were in good agreement with the experiment results in this study, which provide important mechanical parameters for well completion with expandable liner hanger.

\section{Data Availability}

The data used to support the findings of this study are available from the corresponding author upon request.

\section{Conflicts of Interest}

The authors declare that they have no conflicts of interest.

\section{Acknowledgments}

The authors are grateful to the support from the National Natural Science Foundation of China (no. 51574198).

\section{References}

[1] K. H. Ma, D. W. Zhu, L. R. Ma et al., "Advances in liner hanger techniques in deep wells outside China," Petroleum Drilling Techniques, vol. 33, no. 5, pp. 52-55, 2005.

[2] L. R. Ma, Z. H. Guo, X. D. Jiang et al., "Design and application of a new packer liner-hanger," Petroleum Drilling Techniques, vol. 34, no. 5, pp. 54-56, 2006.

[3] K. H. Ma, "A consideration on the development of liner hanger technologies in China," Oil Drilling \& Production Technology, vol. 30, no. 6, pp. 108-112, 2008.
[4] Y. S. Chen, "Development and application of a new doubleslip HPHT liner hanger," Natural Gas Industry, vol. 30, no. 8, pp. 48-50, 2010.

[5] C. L. Ruan, L. Y. Feng, J. F. Zhang et al., "Development and application of liner hanger embedded with slips," China Petroleum Machinery, vol. 40, no. 08, pp. 15-18, 2012.

[6] J. H. Cao and B. Cao, "Analysis on application and benefit of technology of drilling liner hanger," Journal of Tianjin Vocational Institutes, vol. 15, no. 11, pp. 60-64, 2013.

[7] K. Dupal, "Expandable tubular technology: a year of drilling case histories," JPT, Journal of Petroleum Technology, vol. 53, no. 5, pp. 32-34+77, 2002.

[8] Z. H. Guo, L. R. Ma, H. M. Zhu et al., "New development of overseas expandable liner hanger," Drilling Petroleum Techniques, vol. 36, no. 5, pp. 66-69, 2008.

[9] M. Tang, Z. Z. Teng, X. T. Ning et al., Research and Application of Expandable Liner Hanger Oil Drilling \&Production Technology, Society of Petroleum Engineers, vol. 31, no. 6, London, UK, 2009.

[10] H. Q. Yao, L. Y. Ren, Z. H. Guo et al., "Expansion material and expansion approach of expandable liner hanger," Drilling Petroleum Techniques, vol. 38, no. 1, pp. 72-76, 2010.

[11] D. W. Zhu, "Development of overseas novel drilling tool," Sino-Global Energy, vol. 16, no. 4, pp. 41-46, 2011.

[12] F. Liu, X. C. Luo, R. X. Wang et al., "Force analysis of expandable tube for expandable liner," Hanger Oil Field Equipment, vol. 41, no. 1, pp. 30-32, 2012.

[13] G. S. Liu, Y. P. Huang, B. Jia et al., "Application of expandable liner hanger," Petrochemical Industry Technology, no. 7, 2017.

[14] X. G. Bao, "Application and effect of expandable liner hanger in exploratory well," Petrochemical Industry Technology, vol. 25, no. 6, 2018.

[15] T. Walvekar and A. T. Jackson, "Expandable technology improves reliability of conventional liner hanger systems," in Proceedings of the IADC/SPE Drilling Conference, Miami, FL, USA, February 2006.

[16] J. W. Williford and P. E. Smith, "Expandable liner hanger resolves sealing problems and improves integrity in liner completion scenarios," in Proceedings of the Production and Operations Symposium, Oklahoma, OK, USA, March 2007.

[17] A. T. Jackson, B. Watson, L. K. Moran et al., "Development of an expandable liner hanger with increased annular flow area," in Proceedings of the SPE Annual Technical Conference and Exhibition, Denver, CO, USA, September 2008.

[18] C. M. Montanez, S. L. Jensen, D. A. De Clute-Melancon et al., "Expandable liner hanger drill-in capability provides reliable solution for north sea case history," in Proceedings of the SPE Offshore Europe Oil and Gas Conference and Exhibition, Aberdeen, UK, September 2009.

[19] S. Huang, Q. Chen, W. Han et al., "Successful application of expandable liner hanger in ht sidetracking well completion: a case study in liaohe oilfield, China," in Proceedings of the SPE/ IATMI Asia Pacific Oil \& Gas Conference and Exhibition, Jakarta, Indonesia, October 2017.

[20] S. Y. Cui, Y. T. Shao, Y. Wang et al., "Research on expandable liner hanger," Exploration Engineering (Rock \& Soil Drilling and Tunneling), vol. 46, no. 02, pp. 65-70, 2019.

[21] M. Lobo, A. Singhal, C. Lang et al., "A case study of using expandable liner hangers advanced cementation techniques for ERD wells in India," in Proceedings of the SPE Annual Technical Conference and Exhibition, Houston, TX, USA, 2015.

[22] Y. R. He and H. B. Zhu, "Expansion sand screen development and field test," Petroleum Drilling Techniques, vol. 39, no. 03, pp. 106-109, 2011. 
[23] R. Yang, L. Luo, C. L. Shen et al., "Application of the expandable liner hanger in horizontal wells of zhetybai oil field in Kazakhstan," Xinjiang Oil \& Gas, vol. 10, no. 4, pp. 87-89, 2014.

[24] Y. Chen, X. Peng, H. Yu et al., "Mechanical performance experiments on rock and cement, casing residual stress evaluation in the thermal recovery well based on thermalstructure coupling," Energy Exploration \& Exploitation, vol. 35, no. 5, pp. 591-608, 2017.

[25] Y. Chen, T. Liang, X. Peng et al., "Calculation and analysis of the first interface micro-gaps of the thermal production wells," Advances in Mechanical Engineering, vol. 9, no. 2, pp. 1-14, 2017.

[26] Q. Bai, Q. Liu, D. J. Li et al., "Finite element analysis and experimental study of copper suspension system for expandable tubular," Journal of Plasticity Engineering, vol. 25, no. 1, pp. 92-99, 2018.

[27] Z. A. Cai and C. F. Li, "Finite element analysis of the expansion of the twinning induced plasticity steel solid expandable tube," Chinese Journal of Engineering Design, vol. 20, no. 3, pp. 236-242, 2013.

[28] E. Liu, W. Li, H. Cai, and S. Peng, "Formation mechanism of trailing oil in product oil pipeline," Processes, vol. 7, no. 1, p. 7, 2019.

[29] S. Peng, Q. Chen, C. Zheng, and E. Liu, "Analysis of particle deposition in a new-type rectifying plate system during shale gas extraction," Energy Science \& Engineering, vol. 8, no. 3, pp. 702-717, 2020.

[30] Z. Su, E. Liu, Y. Xu, P. Xie, C. Shang, and Q. Zhu, "Flow field and noise characteristics of manifold in natural gas transportation station," Oil \& Gas Science and Technology-Revue D'IFP Energies Nouvelles, vol. 74, p. 70, 2019.

[31] J. J. Chen, D. J. Li, Q. Bai et al., "Calculation model of expansion force based on strain hardening behavior of expandable tubular," Transaction of Materials and Heat Treatment, vol. 38, no. 8, pp. 151-158, 2017.

[32] S. Asghar, M. N. Naeem, M. Hussain et al., "Prediction and assessment of nonlocal natural frequencies of DWCNTs: vibration analysis," Computers and Concrete, vol. 25, no. 2, pp. 133-144, 2020.

[33] M. Taj, M. Arfan, M. Hussain et al., "Non-local orthotropic elastic shell model for vibration analysis of protein microtubules," Computers and Concrete, vol. 25, no. 3, pp. 245-253, 2020.

[34] M. Hussain, M. N. Naeem, A. Tounsi, and M. Taj, "Nonlocal effect on the vibration of armchair and zigzag SWCNTs with bending rigidity," Advances in Nano Research, vol. 7, no. 6, pp. 431-442, 2019.

[35] B. Karami, M. Janghorban, and A. Tounsi, "On pre-stressed functionally graded anisotropic nanoshell in magnetic field," Journal of the Brazil Ian Society of Mechanical Sciences and Engineering, vol. 41, no. 11, pp. 494-511, 2019.

[36] P. Liu, X. H. Xie, W. J. Tong et al., "Finite element analysis and calculation of outer rubber module of expansion tube," Oil Field Equipment, vol. 46, no. 1, pp. 17-21, 2017.

[37] C. F. Li, Z. G. Peng, Y. Q. Wang et al., Nonlinear Finite Element Analysis and Application Examples of Expandable Tubular, China Petrochemical Press, Beijing, China, 2012.

[38] G. M. Qin, D. S. He, L. P. Zhang et al., "Analysis on deformation force of solid expandable tubular based on ANSYS/LSDYNA," Oil Field Equipment, vol. 38, no. 8, pp. 9-11, 2009.

[39] Q. B. Wang, K. Gao, L. Jiang et al., "Numerical simulation of solid expandable tubular based on ABAQUS," Oil Field Equipment, vol. 45, no. 2, pp. 54-57, 2016.
[40] T. Li, F. P. Li, L. X. Zhang et al., "Simulative study of driving force for solid expandable tubular," Oil Field Equipment, vol. 42, no. 2, pp. 39-42, 2013.

[41] B. Yue, K. C. Man, D. Walters et al., Tension and Expansion Analysis of Pipe-In-Pipe Risers: Part B Finite Element Modeling, International Society of Offshore and Polar Engineers, Anchorage, Alaska, 2017.

[42] E. R. Malta and C. d. A. Martins, "Finite element analysis of flexible pipes under compression: influence of the friction coefficient," in Proceeedings of the 35th ASME International Conference on Ocean, Offshore and Arctic Engineering, Busan, South Korea, December 2016.

[43] R. Provasi, F. G. Toni, and C. de A. Martins, "A frictional contact element for flexible pipe modeling with finite macro elements," Journal of Offshore Mechanics and Arctic Engineering-Transactions of the ASME, vol. 140, no. 5, Article ID 061601, 2018.

[44] X. L. Yang, "Experimental study of hanging force of solid expandable tubular based on metal seal," Oil Field Equipment, vol. 44, no. 8, 2015.

[45] L. Gu, F. Han, M. Liu et al., "Research on improving the load capacity of expandable liner hanger," Petroleum Drilling Techniques, vol. 44, no. 4, 2014.

[46] J. Zhang and J. Xie, "Effect of reservoir's permeability and porosity on the performance of cellular development model for enhanced geothermal system," Renewable Energy, vol. 148, pp. 824-838, 2020.

[47] J. Zhang, H. Zhang, and L. Zhang, "Buckling response analysis of buried steel pipe under multiple explosive loadings," Journal of Pipeline Systems Engineering and Practice, vol. 11, no. 2, Article ID 040200, 2020.

[48] H. Patel, S. Salehi, R. Ahmed, and C. Teodoriu, "Review of elastomer seal assemblies in oil \& gas wells: performance evaluation, failure mechanisms, and gaps in industry standards," Journal of Petroleum Science and Engineering, vol. 179, pp. 1046-1062, 2019.

[49] A. Zhong, D. Moeller, and S. Maddux, "Development of a high hang weight expandable liner hanger for deepwater applications," in Proceedings of the Offshore Technology Conference, Houston, TX, USA, May 2017.

[50] H. Patel and S. Salehi, "Investigation of elastomer seal energization: implications for conventional and expandable hanger assembly," Energies, vol. 12, no. 4, p. 763, 2019.

[51] S. A. Al-Hiddabi, T. Pervez, S. Z. Qamar, and etal, "Analytical model of elastomer seal performance in oil wells," Applied Mathematical Modelling, vol. 39, pp. 236-2848, 2015. 